
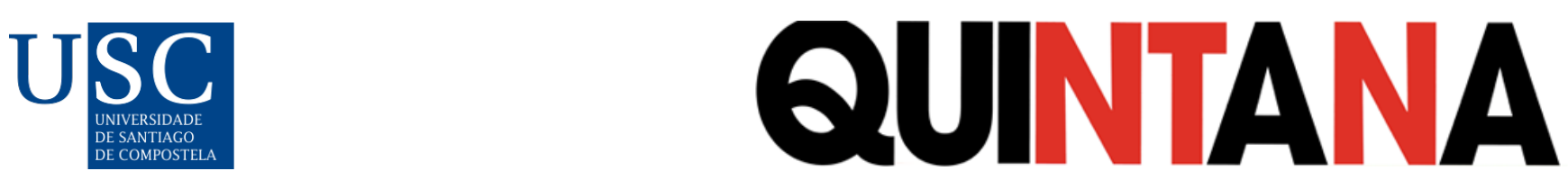

Quintana: revista do Departamento de Historia da Arte, (20), 2021. ISSN-e: 2340-0005

https://doi.org/10.15304/quintana.20.8073

Reseñas

\title{
Exposiciones y comisariado. Relatos cruzados. Olga Fernández López, Ediciones Cátedra, Madrid, 2000. 280 págs. ISBN 978-84-376-4135-5
}

\author{
Rocío Robles Tardío ${ }^{1}$ (D) \\ ${ }^{1}$ Universidad Complutense de Madrid, España
}

En las primeras páginas del libro Exposiciones y comisariado. Relatos cruzados, su autora, Olga Fernández López, presenta el marco de su trabajo de manera clara y concisa -la historia de las exposiciones y del comisariado-, algunos de los problemas o vicios intrínsecos con los que ha tenido que lidiar para concluir satisfactoriamente su objetivo - "escasez de fuentes para su reconstrucción histórica", así como una historia del arte enquistada en la historia de los artistas y sus obras - y lo que reconocemos como su lugar de enunciación - el ámbito académico, en cuanto profesora e investigadora en el Departamento de Historia y Teoría del Arte de la Universidad Autónoma de Madrid-, una realidad donde reside en gran medida el valor de su gesta. Así, la premisa que señala al inicio de su trabajo: que el alcance y calado político y social de las exposiciones ha encontrado antes el interés de los comisarios que el de los historiadores, constituye, en cierta manera, el hilo del que tira para construir un relato de relatos, a la vez que la cuerda que remonta para reivindicar el lugar del historiador en la narración del arte contemporáneo.

Olga Fernández López cuenta con una reconocida trayectoria tanto en el ámbito académico como en el profesional, donde cabe mencionar que fue conservadora jefe y jefa de Investigación y Educación en el Museo Patio Herreriano de Valladolid (2001-2006), completó su formación académico-investigadora en The Royal College of Art de Londres y ha comisariado varias muestras, siendo el proyecto más reciente Mil bestias que rugen. Dispositivos de exposición para una modernidad crítica (Centro Andaluz de Arte Contemporáneo, 2017). En una primera aproximación, este libro conjuga sus intereses como docente e investigadora y en él emplea una mirada tan lúcida como crítica para la comprensión de una modernidad/ contemporaneidad sustentada en un sistema en constante reinvención. En este sentido, esta es una de las propuestas de su libro: volver a revisar y analizar el relato de la modernidad para complejizarlo, abriéndolo y haciéndolo plural, situando para ello - y he aquí su principal contribución - a las exposiciones en el hipocentro y al fenómeno del comisariado en el epicentro de una aproximación a la historia del arte contemporáneo desde el análisis del valor de las fallas y pliegues resultantes. Con este acertado cambio de foco, Olga Fernández López tensiona el relato hegemónico — de la historia del arte contemporáneo, de los espacios e instituciones, de los movimientos, los escenarios y sus protagonistas- desde dentro y aplica una clave que sino sísmica, sí plástica u orgánica que incorpora en todo momento a los contextos. 
El resultado es un mapa dibujado con suma atención de aquello que, por contacto o por dispersión, se sitúa en ese rango heterogéneo que va de la exposición al trabajo del comisario y al valor del comisariado que genera, a su vez, nuevos modelos o géneros expositivos, desde el cambio del siglo XIX al XX y hasta nuestros días. Como apunta, esta revisión o repaso no se queda en el espacio en sí -ocupándose a este respecto de los usos y la adjetivación de este y, por lo tanto, yendo más allá de las políticas espaciales que han dominado los estudios sobre historia de las exposiciones y del comisariado (p. 21)—. Además, si por un lado el libro participa en los estudios curatoriales y contribuye a la necesidad de revisión (y superación) de las exposiciones como relatos lineales y del papel protagonista del MoMA, erigido en y asumido como el gran paradigma o espejo en el que las instituciones consideradas menores - real o metafóricamente hablando-se han mirado y comparado; por otro lado, y entre líneas, vendría a lanzar una llamada de atención sobre el inmanejable superávit de comisarios y comisarias en la actualidad -y la consiguiente multiplicación exponencial de las prácticas curatoriales-, quienes se mueven entre la ingenuidad y falta de referencias fundamentales y el reclamo y construcción de su pretendida genealogía.

El presente trabajo se revela necesario y oportuno por varios motivos. En primer lugar, por el planteamiento claro y la visión global que arroja sobre el tema (las exposiciones), señalando su valor como clave de análisis sociopolítico, artístico, estético e institucional (o anti institucional). También se debe mencionar el ingente esfuerzo de la autora para detectar, explicar y contextualizar conceptos y categorías desde las prácticas mismas; a ello se añade la relectura contextualizada que lleva acabo de nombres y lugares comunes, matizando el halo de genialidad o reconociendo el carácter de excepcionalidad con el que la historiografía los ha construido y cuya vigencia se prolonga en el tiempo (Richard Hamilton, documenta 5, Jean-Hubert Martin, por ejemplo). Otra de las razones que lo convierten en un libro de base y consulta necesaria para iniciarse en el tema y/o consolidar el conocimiento sobre este se encuentra en el compendio bibliográfico que reúne, presentándose como un repositorio o catálogo crítico actualizado, único en castellano, de referencias fundamentales en el ámbito de los estudios curatoriales, la historia de las exposiciones, las políticas institucionales de los museos y las prácticas artísticas contemporáneas (entendidas más allá del objeto), lo cual hace que sea un título irrenunciable en las bibliografías de todo estudioso o toda estudiosa que se preste. Además del texto original por sí mismo, Olga Fernández López también desempeña una reseñable tarea de editora, pues apoya sus argumentos e interpretaciones en una selección de textos fundamentales con los que construye - mediante citas $\mathrm{y}$ fragmentos - un generoso repertorio de fuentes primarias y secundarias traducidas por ella y que cierran cada uno de los seis capítulos en que se estructura el libro.

En este sentido, Exposiciones y comisariado. Relatos cruzados sobresale por méritos propios en la escasa bibliografía en castellano sobre la historia de las exposiciones y las prácticas curatoriales, a la vez que la autora se presenta como máxima especialista en la literatura crítica y bibliografía actual internacional sobre el tema. El aparato visual merece ser citado también, pues conforma un abanico de imágenes elocuentes - algunas menos conocidas que otras, lo que siempre funciona como un aliciente y es recibido con interés por el lector - que ahora dispuestas y ordenadas atendiendo a nuevos parámetros clasificatorios a la luz de las propias prácticas expositivas y curatoriales, atravesadas a su vez por las categorías del pensamiento contemporáneo o su revisión (fetiche, autor, memoria, archivo, museo, instalación, etc. ), ilustran con lógica y ritmo los temas, escenarios y prácticas que se estudian en cada uno de los seis capítulos y los abundantes epígrafes en los que se articula el libro. Además, y en último lugar, Olga Fernández López maneja los recursos del lenguaje y la narración, sin caer en los vicios de la retórica ensimismaba y autorreferencial que abunda en 
textos actuales sobre arte contemporáneo, sus prácticas y sus escenarios. De ahí su pertinencia, pues al margen de modas o intereses efímeros, se trata de un libro que es resultado de una extensa investigación y del destilado crítico de datos, hechos e informaciones, donde conviven trabajo y metodología, erudición y voluntad de transferencia.

El sugerente índice adelanta al lector que el libro está bien armado, aunque la propuesta puede resultar compleja; esta se articula mediante conceptos, escenarios, actitudes y prácticas, de manera que el factor cronológico deja paso a un relato procesual - sincrónico en algunos casos e incluso de idas y venidas en otros-, para detenerse en los cambios (De la galería al cubo blanco), en los puntos de inflexión (Desmaterialización y deslocalización), en los fenómenos (Exposiciones y activismo; La bienalización del arte), en las propuestas radicales que han torcido, quebrado, superado y reñazado el "como las cosas deben ser" (Artistas y comisarios; Enciclopedias chinas; Heterotopías y museos), hasta llegar a la heterogeneidad y polisemia de los términos comisario y exposición de nuestros días (La ansiedad comisarial; Los nuevos géneros de arte público). La arquitectura conceptual y los enunciados del libro se condensan y pliegan en seis capítulos, en este orden: 1. El espacio expositivo y sus galerías; 2. Comisarios (in)dependientes; 3. El poder del display; 4. Comisariar el mundo; 5. El (des)orden de las cosas; 6. El comisariado en el campo expandido. Con ellos, o a través de ellos, Olga Fernández realiza un riguroso repaso por todo un entramado de nombres (entre otros Marcel Duchamp, El Lissitzky, Willem Sandberg, Marcel Broodthaers, Harald Szeemann, Seth Siegelaub, Lucy Lippard; de manea que, además de artistas, convoca también a arquitectos, críticos, directores de museos, historiadores del arte, asociaciones y colectivos ciudadanos, etc.), geografías o espacios, ya sean instituciones, oficinas (Estética de oficina y desmaterialización), casas (Arte en los apartamentos), jardines (Arte al aire libre) o la calle (Exposiciones de resistencias). Así es como logra tejer una breve pero verídica historia del arte contemporáneo desde la perspectiva de las exposiciones y el valor del comisariado, "con el fin de reflexionar sobre los modos en que las imágenes -y las actitudes, añado ahora- construyen nuestro conocimiento del mundo” (p. 76). En esta voluntad enciclopédica reside el valor del libro.

La exhaustiva tarea que Olga Fernández López se propone y logra no excluye la perspectiva feminista, la cual queda patente — sin tener que señalarla o insistir en ella - al poner sobre la mesa y manejar concienzudamente un abundante y mayoritario número de trabajos de investigación y estudios críticos realizados por historiadoras del arte, críticas, comisarias, directoras de museos o profesoras de universidad, a las que Fernández López se suma ahora por derecho propio. El libro, en cuanto ejercicio de escritura, se construye siguiendo recursos característicos de la técnica del montaje cinematográfico y está atravesado, además, por otras metodologías y perspectivas, como la antropología (Enciclopedias chinas), la etnografía, la historia del arte propiamente, los estudios culturales o los estudios poscoloniales (Los mapas del arte).

En definitiva, no es el propósito del libro definir qué es un comisario, como tampoco qué es una exposición; en cambio, la autora se pregunta primero y responde a continuación de manera argumentada qué puede una exposición y qué puede un comisario, cuál es el alcance de una y otro en la poliédrica experiencia en el mundo contemporáneo, que se despoja paulatinamente del adjetivo internacional para vestirse de global, un proceso que corre paralelo a la expansión de la perspectiva de ejes (centros y periferias). En el libro lo afirma así: "El conocimiento cada vez más profundo de las producciones nacionales y diaspóricas ha convertido a las exposiciones en una herramienta fundamental a la hora de sintetizar y divulgar una historia del arte moderno en clave global, como demuestran los proyectos Global Conceptualism: Points of Origins, 1950s-1980s (1999) o The World Goes Pop (2015). En todo este proceso comprobamos cómo algunas investigaciones 
comisariales han ido por delante de las de los historiadores, lo que ha convertido las exposiciones en un innegable ámbito discursivo, pese a, como hemos señalado, la persistencia de las metrópolis historiográficas" (p. 141). El estudio y consideración de las exposiciones por su dimensión histórica le lleva a abundar en la exposición como espacio de intercambio, construcción y mediación; y presentar al comisario como un amplio abanico de posibilidades, perfiles, propósitos, denuncias y rupturas, fuerzas intelectuales, necesidades sociales, artistas, organizadores o programadores, entre otras opciones.

A este respecto, y atendiendo a lo mencionado, Exposiciones y comisariado. Relatos cruzados cumple dos propósitos no enunciados abiertamente por la autora, pero que tras la lectura cabe intuir que los ha situado estratégicamente en el centro de su trabajo. El primero es el lugar que reserva a la labor, las propuestas y la persona de Harald Szeemann, quien aparece en el segundo capítulo y se instala como bajo continuo o elemento vertebrador del texto. No obstante, lejos de dejarse eclipsar por esta figura emblemática, Olga Fernández López analiza sus exposiciones, proyectos, actitudes y decisiones en el contexto de lo que sucede también alrededor de él, pudiendo así calibrar la radicalidad y originalidad de sus gestos y las resonancias de estos en las prácticas curatoriales desde la década de los años 50 hasta nuestros días.

En este sentido, y a modo de recapitulación, a lo largo del libro y en la sucesión de escenarios, la autora se aproxima a la resbaladiza figura del comisario de arte contemporáneo — desde su continua transformación - atendiendo a las tareas materiales o las propuestas intelectuales que este asume y desempeña, partiendo de la tentativa de Szeemann de calificar al comisario como exhibition organizer hasta llegar al curationism como síntoma y categoría, y a la figura del comisario que, consustancial a su ejercicio crítico, propone expandir los formatos de las exposiciones, como ejemplifica Hans Ulrich Obrist. Todo ello da cuenta de la relación de simbiosis que se establece entre exposición y comisario/comisariado en sus historias y en los relatos cruzados que generan. Es decir, la variedad de prácticas, agentes, sujetos y procesos afectan a su vez a la extensión, ampliación y transformación de los modelos expositivos y de los espacios de exposición en la actualidad y que parecen guiar el futuro, "tanto dentro como fuera del cubo blanco" (p. 247), como concluye la autora. El segundo propósito refiere a una de las primeras reflexiones que Olga Fernández López hace al inicio del libro y que servía como detonador de este, así como de la presente reseña: que "el interés por la dimensión histórica de las exposiciones se establezca antes en el ámbito del comisariado que en el académico"; por lo que valdría concluir, como ella hace de manera exitosa, que Exposiciones y comisariado. Relatos cruzados viene a ajustar esa balanza. Su trabajo no es una mera monografía de alcance universitario, sino que abre una interesante senda para repensar críticamente y también en perspectiva el papel de las exposiciones y el comisario en el mundo actual, insertos en espacios otros y donde lo glocal convive con el ensimismamiento de los discursos y las prácticas. 